\title{
Research on Maintenance Training System of Semi Physical Equipment Fire System
}

\author{
Da XU, Wen-Bo FAN ${ }^{\text {a }}$ and Ye LUO \\ Department of Arms Engineering, Academy of Armored Force Engineering, Beijing, 100072, China \\ a1976257507@qq.com
}

Keywords: Equipment, Fire system, Maintenance training, The semi physical simulation.

\begin{abstract}
Aiming at the existing problems of traditional equipment fire system maintenance training, the semi physical maintenance training is researched, analyzes the main task of fire system maintenance training, researches on key technology of semi physical maintenance training system, makes the overall design of maintenance training system, provides an effective means for the maintenance training of equipment fire system.
\end{abstract}

\section{Introduction}

With the continuous development of equipment technology, the high and new technology has been integrated into the new armored equipment, which makes it become a complex system of light, mechanical, electrical and liquid integration from the simple mechanical system. The complexity of armored equipment resulting in the armored equipment support unit single mechanical and electrical repair personnel repair personnel are difficult to repair the fault exclusion, it is an urgent need for training of equipment maintenance personnel with comprehensive repair ability of light, mechanical, electrical and liquid integration.

The traditional maintenance training is carried out in a real armored equipment, its advantage is that the trainees have good hands-on ability, its disadvantage is that it will cause a loss of equipment, and the training cost is higher. The virtual maintenance training system sets all kinds of faults in the virtual system, enables trainees to grasp the method of eliminate all kinds of faults, deepens the understanding of equipment maintenance and intuitive feeling. But the virtual environment cannot give the trainees the real feel, it can only be used as an important part of equipment maintenance training. Semi physical maintenance training imitates the structure characteristics of real equipment, the maintenance and training in equipment is basically the same to the real maintenance environment, it enhances the trainees' ability to test and diagnose fault, remove failures. It meets the training needs of troops effectively[1]. In this paper, taking equipment fire system as an example, research on and realize the Semi physical maintenance training system.

\section{Analysis of Fire System Maintenance Training Task}

Equipment maintenance training task analysis is an important part of equipment maintenance support task. Maintenance training task analysis is the analysis on the contents of the maintenance and support of the equipment. In the process of the design of maintenance training system, it needs to refine and adjust the maintenance training tasks. Maintenance training task analysis relies on the maintenance training task plan, and support the decision to carry out maintenance training, as resources of the maintenance training in the deployment tasks subsequently. The main flow chart of equipment maintenance training task analysis is shown in the figure 1. 


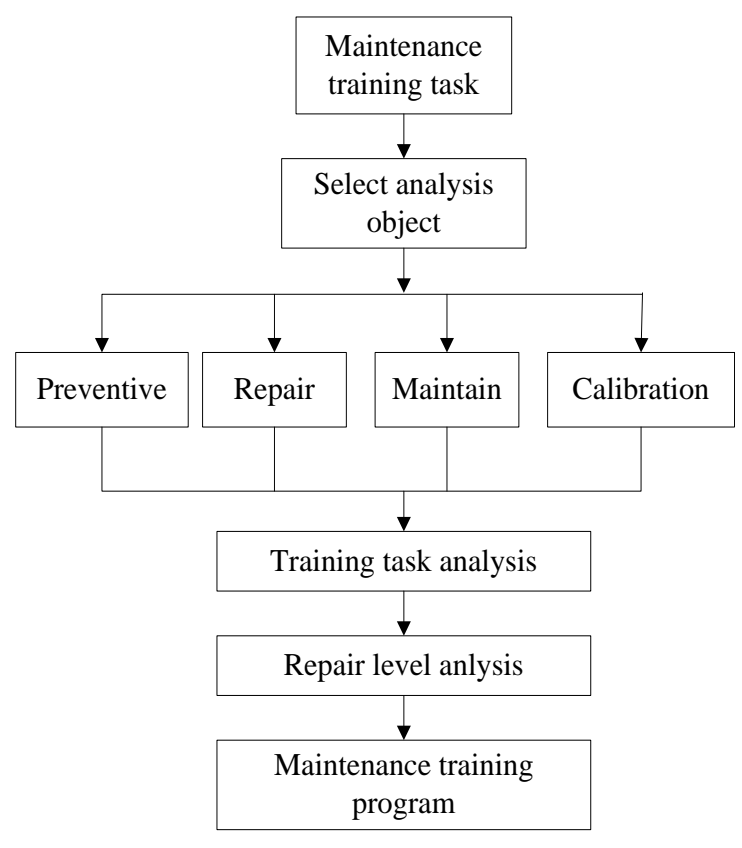

Figure 1. Flow chart of equipment maintenance training task analysis

\section{Composition of Fire System}

The equipment fire system, takes tank for example, includes tank artillery, automatic loading machine, machine guns and ammunition, it is a general term for devices used for killing and destruction.

\section{Main Content of Fire System Maintenance}

(1) Gun maintenance, copper removal, inspection, repair and replacement of gun barrel reaching life limit;

(2) The main components should be inspected, disassembled, decomposed, cleaned, identify their components and parts, which do not meet the requirements of the equipment technical, should be repaired or replaced;

(3) Check in the recoil mechanism, counter-recoil mechanism, elevation machine and traversing machine, if there is a fault or liquid deterioration, remove the decomposition, cleaning, identification, removal of rust, and replace or repair those do not meet the requirements of the technical requirements of repair parts;

(4) Repair or replacement of canvas products and other non - metal parts;

(5) Paint off those parts need to be repaired.

\section{Fire System Maintenance Training Mission}

According to the content and scope of the tank fire system maintenance, combined with the structure and common fault of each component of the fire system, the basic task of the fire system maintenance training is summarized:

(1) Using and maintenance of ordnance inspection repair tools;

(2) The use maintenance, disassembly, disassembly, cleaning, identification, troubleshooting, installation and assembly of artillery parts;

(3) The maintenance, decomposition, troubleshooting and assembly of turret door, turret and turret ring fixator;

(4) The decomposition, troubleshooting, adjustment and assembly of automatic loading machine;

(5) The maintenance of the various parts of artillery and automatic loading machine. 


\section{Analysis on Key Techniques of Maintenance Training System}

\section{Hardware in the Loop Simulation Technology}

The semi physical simulation is the process of combining the mathematical model with physical model. In the semi physical simulation, a relatively simple system or more clearly on the rule of the part is establishment of mathematical model, and implemented in a computer; the more complex parts or the parts law is not clear, directly using physical model or real ${ }^{[2]}$.

The establishment of a simulation system is oriented to a certain system and problem. The composition of the simulation system depends on the system studied. Problem oriented simulation system block diagram shown in figure 2 .

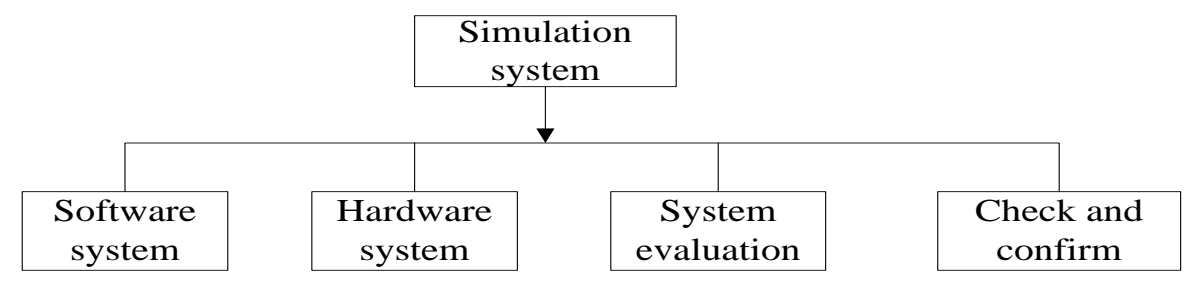

Figure 2. Problem oriented simulation system block diagram

Using the semi physical simulation technology, the evaluation use mathematical model, the fault setting use physical model, realize each part of the fire system use semi physical equipment instead of real equipment, make the maintenance training to achieve the optimization effect.

\section{Fault Setting Technique}

In order to make the fault setting, we must know all kinds of faults of the system, only to grasp the information of the fault, we can effectively set up the fault according to the specific situation, so that maintenance personnel can train in the case of failure. Fault information mainly includes the failure phenomena, causes of failure, the mechanism of failure and troubleshooting [3].

\section{Assessment Technology}

Maintenance training evaluation is an important part of weapon equipment maintenance training platform [4]. Fire equipment maintenance training evaluation system mainly includes theoretical test and practical operation, for there are many structures in artillery and automatic loading machine, so do fault type and fault caused by the complicated factors, so the level of analysis and evaluation technology and the fuzzy comprehensive evaluation assessment are used for maintenance training system.

\section{The Principle of Assessment and Evaluation}

(1) The principle of comprehensive evaluation system: first of all, the content should be fully and truly reflect the various aspects of the evaluation object, so as to meet the requirements of the quality comprehensive evaluation object, the evaluation criteria must be hierarchical and specific.

(2) The principle of Science: the establishment of the evaluation system must use scientific ideas and methods, such as evaluation index weight calculation and evaluation methods must have the theoretical basis, determine the different emphasis according to the actual situation.

(3) The principle of fairness: the establishment of the evaluation system must meet the objective facts, to reflect the quality of the assessment object objectively and truly.

(4) Operational principle: the evaluation index is easy to obtain and easy to quantify, the meaning of each index is clear, the calculation is not too complex, so as to ensure the operability of the evaluation system [5].

\section{The Construction of Evaluation System}

(1) Determine the evaluation factor set 
Evaluation factors should adhere to the principle of systematic, independent, and subjective and objective, to define and data collection work.

(2) Determine the reviews set

According to the content of the study to determine the level of the indicators, generally divided into \{excellent, good, qualified, unqualified \}.

(3) Determine the weight of evaluation factors

By using analytic hierarchy process and expert weighting method, the weight of evaluation index is given.

(4) The implementation of evaluation, statistical data

Evaluation personnel given the assessment level of the proposed layer by layer to establish assessment factors and assessment of the fuzzy relationship between the matrix $\mathrm{R}$ and the corresponding weight coefficient set Ai.

(5) Data processing, the results of the evaluation.

The fuzzy comprehensive evaluation model is used to evaluate the fuzzy relation matrix of each assessment level. The evaluation matrix B is obtained, and the normalization of the evaluation matrix $\mathrm{B}^{\prime}$ is obtained and the final evaluation results are obtained.

\section{Overall Scheme Design of Maintenance Training System}

The overall scheme of firepower system of armored equipment maintenance training should be designed to meet the task of teaching and training needs as the starting point, and at the same time, taking into account the teaching demonstration and practical operation.

\section{Maintenance Training System Function}

(1) Fault setting and eliminating function. Semi physical maintenance training system could set fault according to different training courses and different trainees to each component, and troubleshooting by trained personnel.

(2) Teaching demonstration function. Be able to achieve the synchronization action in the loop fire system equipment maintenance training system, and to facilitate teachers to explain and troubleshooting.

(3) Evaluation function. Be able to carry out the assessment of maintenance personnel basic knowledge, basic theory, fire system disassembly and troubleshooting, and can achieve the scoring record and query results. To facilitate teachers to understand the students' ability of knowledge and practical operation.

\section{Design Requirement}

The design requirements of maintenance training system for semi physical fire system are mainly [6]:

(1) The shape, connection relation and relative position of the maintenance training simulation system are lifelike with the real;

(2) Maintenance training system is similar to equipment performance index function could be lower than the actual index, but should be able to measure and adjust;

(3) Maintenance training system for each analog interface components of electrical and physical characteristics are consistent with the actual standard;

(4) The fault can be set up in the system, the number of faults, the types can be upgraded and extended;

(5) The system can realize the interactive fault detection and elimination;

(6) According to the fault phenomena, the system can demonstrate and test equipment system fault analysis, positioning and troubleshooting methods.

\section{The Overall Program Design}

According to the requirement of fire system maintenance training function, using the semi physical simulation, program control, load simulation technology, while the thermal system is divided into 
several subsystems, realize the fault setting, fault detection, fault diagnosis training, maintenance training and evaluation functions of the maintenance training system.

\section{The Implementation of Maintenance Training System}

Semi physical maintenance training system adopts master-slave control structure, which mainly consists of five parts, the console, the simulation system components and cable, demonstration system, bus system and software system. Its block diagram is shown in Figure 3.

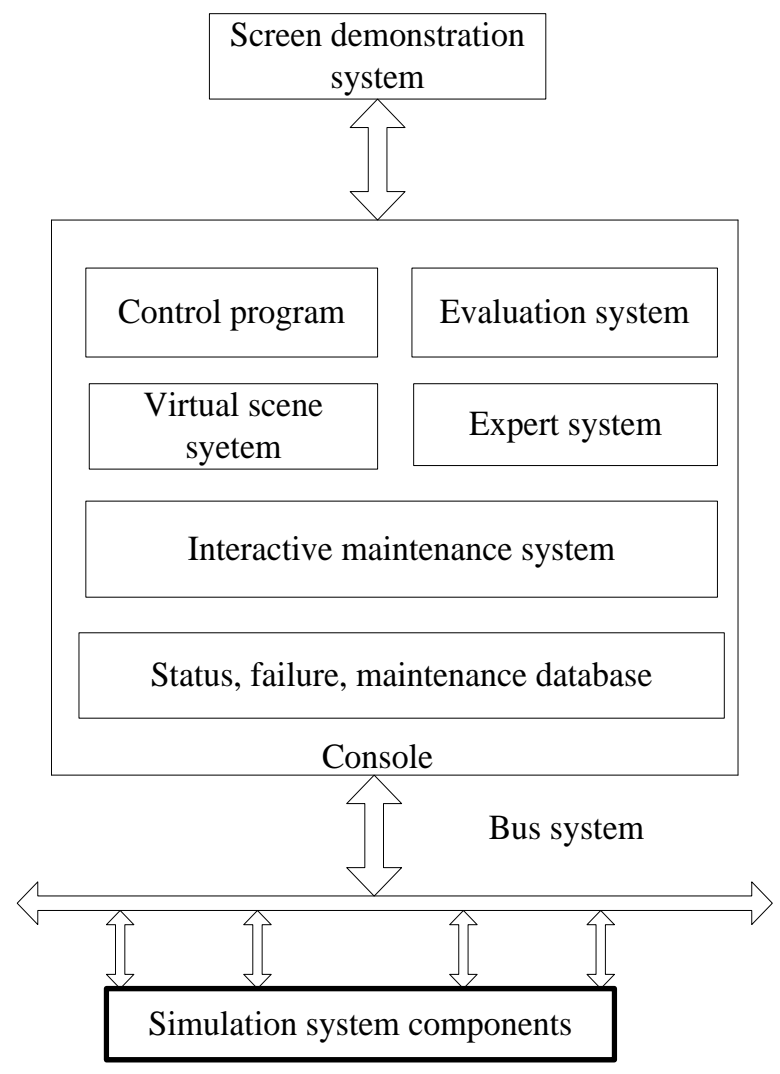

Figure 3. Semi physical maintenance training system block diagram

The software system is mainly composed of failure and maintenance database, virtual visual display, state control program, expert system, maintenance training system, evaluation system and demonstration system, as shown in figure 4 .

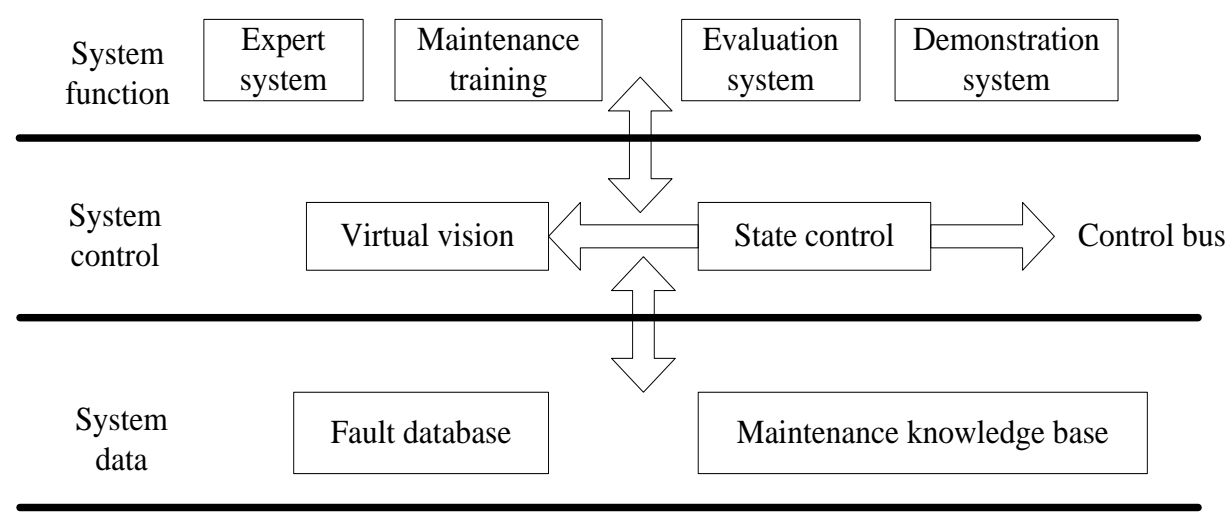

Figure 4. The software system block diagram 


\section{Conclusion}

In this paper, based on the analysis of the fire system maintenance tasks, the key technology and the overall program of the hardware in the loop maintenance training system are studied. This system not only can save the cost of training, but also give the trainees the real maintenance environment to a maximum degree, can replace the actual equipment to carry out maintenance training well, provides an effective means for the training of maintenance training.

\section{References}

1. Wei-bing Bai, Guang Hong, Zhen Yang. Maintenance\& Training System Design Based on Hardware-in-the-loop Simulation and Virtual Maintenance Technology [J]. Instrumentation Technology, 2014, (10):7-9.

2. Jian-qiang Huang, Jian-bo Ju. Development Introduction of Hardware-in-the-loop Simulation [J]. Ship Electronic Engineering, 2011, 31(7):5-7.

3. Jia Zhang, Hao Jiang. Research of failure setting principle on maintenance training system [J]. Electronic Design Engineering, 2015, 23(18): 110-112.

4. Xiang-rong Li, Cai-Yan Yue, Guo-hui Wang. Design of Half-Practicality Maintenance Training Check and Evaluation System [J]. Journal of Ordnance Equipment Engineering, 2013, 34(6) :11-13.

5. Mao-yun Guo, Xiang Yi. Researches on Appraisal and Evaluation Based on Analytic Hierarchy Process and Fuzzy Comprehensive Evaluation [J]. World Sci-Tech R \& D, 2010, 32(5) :719-722.

6. Yong Cao, Xin Su, Si-jie Shao. Design and implementation of maintenance training system under pattern of synthetic simulation [J].Computer Engineering and Applications, 2012, 48(S2): 100103. 